\title{
Rotavírus bovino: fatores de risco, prevalência e caracterização antigênica de amostras em rebanhos leiteiros no estado de São Paulo
}

\author{
[Rotavirus in cattle: risk factors, prevalence and antigenic characterization from dairy calves' \\ samples in São Paulo State, Brazil] \\ P.P.S. Freitas ${ }^{1}$, S.A. Uyemura ${ }^{3}$, D.G. Silva ${ }^{1}$, S.I. Samara ${ }^{2}$, M.G. Buzinaro ${ }^{2 *}$ \\ ${ }^{1}$ Aluna de pós-graduação - Faculdade de Ciências Agrárias e Veterinárias - UNESP \\ Campus de Jaboticabal, SP \\ ${ }^{2}$ FCAV - UNESP, Campus de Jaboticabal \\ Via de Acesso Prof. Paulo Donato Castellane, s/n \\ 14884-900 - Jaboticabal, SP \\ ${ }^{3}$ Faculdade de Ciências Farmacêuticas - USP - Ribeirão Preto, SP
}

\begin{abstract}
RESUMO
O estudo de prevalência da infecção por rotavírus em bezerros abrangeu 51 rebanhos leiteiros, escolhidos ao acaso, localizados em uma região produtora de leite do estado de São Paulo. Entre 31 de maio e 20 de outubro de 2003, foram colhidas 103 amostras de fezes de bezerros com diarreia e 308 amostras de animais sem diarreia, com idade entre um e 45 dias. As amostras foram analisadas pelas técnicas de ensaio imunoenzimático (EIE) e eletroforese em gel de poliacrilamida (PAGE). Pelo EIE foi observada prevalência de rotavírus de 21,6\% (11/51) nos rebanhos e 6,7\% (27/404) nos bezerros. Foram diagnosticados animais infectados por rotavírus tanto em bezerros diarreicos $(18,4 \% ; 19 / 103)$ quanto em bezerros assintomáticos $(2,7 \% ; 8 / 301)$. A maior frequência de infecção foi determinada em bezerros com idade entre um e 15 dias, sendo estabelecida uma relação inversa entre a frequência de positividade e a idade dos animais $(\mathrm{P}<0,05)$. Além da idade, o sistema de alimentação - fornecimento manual do leite ou bezerro com a mãe, o tipo de instalação - baias individuais ou baias coletivas - e o tamanho do rebanho -, número de matrizes foram fatores que influenciaram significativamente a frequência da infecção $(\mathrm{P}<0,05)$. O RNA extraído de 27 amostras pelo PAGE foi classificado em sete eletroferótipos, indicando grande diversidade genômica de rotavírus. A genotipagem das amostras positivas para rotavírus foi realizada pelo método de transcrição reversa-reação da polimerase em cadeia, destacando a presença de infecções pelos genótipos G6P[5] e G10P[11].
\end{abstract}

Palavras-chave: bezerro, rotavírus, diarreia, fatores de risco, genotipagem

\begin{abstract}
The study on rotavirus infection prevalence in calves was undertaken in 51 dairy cattle herds, randomly selected, in a dairy area in the state of São Paulo. One hundred and three samples of feces from calves with diarrhea and 308 samples of feces from calves free from the disease, age ranging from 1 to 45 days, were collected from May $31^{\text {st }}$ to October $20^{\text {th }}$ 2003. Stool samples were analyzed through immunoenzymatic assay techniques (IEA) and polyacrylamide gel electrophoresis (PAGE). Rotavirus prevalence rate of 21.6\% (11/51) was detected by IEA in cattle herds and 6.7\% (27/404) in calf population. Rotavirus infection was diagnosed in calves with diarrhea (18.4\%; 19/103) and in clinically healthy calves (2.7\%; 8/301). The highest infection frequency was found in calves aged 1 to 15 days. There is an inverse relationship between positive frequency and age of animals $(P<0.05)$. Factors which may affect rotavirus prevalence in herds, such as type of meals (manual milk supply or calf with dame), enclosure (individual or collective pens), herd size (number of matrixes) and age have been analyzed by the chi-square test, and significantly affected infection frequency ( $p<0.05)$. RNA from 27 positive samples by PAGE were classified in seven electrophorotypes and showed the rotavirus' extensive genomic diversity. Rotavirus positive samples genotyping was undertaken through the
\end{abstract}

Recebido em 29 de abril de 2011

Aceito em 27 de junho de 2011

*Autor para correspondência (corresponding author)

E-mail: glorinha@fcav.unesp.br 
reverse transcription-polymerase chain reaction $(R T-P C R)$, underpinning infections by special genotypes $G 6 P[5]$ and G10P[11].

Keywords: calf, rotavirus, diarrhea, risk factors, genotyping

\section{INTRODUÇÃO}

As enterites em bezerros estão entre as principais causas de morbidade e mortalidade e acarretam graves prejuízos à pecuária (Snodgrass et al., 1986; Klingenberg e Svensson, 1998). Estudos epidemiológicos realizados em vários países apontam os rotavírus como agentes etiológicos importantes das enterites que afetam os bezerros principalmente nas primeiras semanas de vida (Woode e Bridger, 1975; DeLeew et al., 1980; Fijtman et al., 1987; Luchelli et al., 1992). No Brasil, as infecções por rotavírus já foram assinaladas em diversas propriedades de criação de bovinos, demonstrando que este agente encontra-se bastante disseminado (Buzinaro et al., 2000; Brito et al., 2000; Alfieri et al., 2004; Alfieri et al., 2006).

Pertencente à família Reoviridae, o rotavírus apresenta genoma segmentado formado por 11 segmentos de RNA de cadeia dupla, rodeados por um capsídeo formado por três camadas de proteínas (Estes e Cohen, 1989). As proteínas do capsídeo externo VP4 (codificadas pelo segmento genômico 4) e VP7 (codificadas pelos segmentos 7, 8 ou 9) induzem a produção de anticorpos neutralizantes sorotipos específicos, definindo a base da classificação viral em sorotipos P (VP4) e G (VP7) (Taniguchi et al., 1993). O uso de técnicas imunológicas, como o ensaio imunoenzimático (Bellinzoni et al., 1989), e métodos moleculares, como a reação em cadeia da polimerase (Gouvea et al., 1990), possibilitam a determinação das características antigênica e molecular de estirpes de rotavírus bovino. Essas informações são importantes para o estabelecimento de ações epidemiológicas e também para o desenvolvimento e monitoramento de vacinas utilizadas na prevenção e no controle das diarreias neonatais.

A grande quantidade de partículas virais eliminadas nas fezes dos animais infectados e a resistência das partículas ao meio ambiente facilitam a contaminação ambiental e o ciclo de infecção nos rebanhos (Bridger, 1994). Além da resistência da partícula viral, aspectos ligados ao ambiente, manejo, nutrição e estado imune dos animais são considerados como fatores de risco para bezerros leiteiros e podem contribuir para aumentar a incidência da rotavirose nos rebanhos (Reynolds et al., 1986; Fernandes et al., 1998).

Os objetivos deste estudo foram determinar a prevalência de rotavírus em bezerros de rebanhos leiteiros de uma importante região produtora de leite do estado de São Paulo e estudar os efeitos de idade, raça, tipo de alojamento, sistema de alimentação, tamanho dos rebanhos e estação de parição sobre a prevalência de rotavírus e a caracterização dos genótipos $\mathrm{G}$ e $\mathrm{P}$ das estirpes de rotavírus circulantes.

\section{MATERIAL E MÉTODOS}

O estudo de prevalência de rotavírus abrangeu rebanhos bovinos leiteiros localizados no município de São Carlos, estado de São Paulo, pertencentes a produtores associados a uma cooperativa de laticínios e selecionados por meio de sorteio, entre os rebanhos da região. No período da amostragem, a cooperativa contava com 438 produtores, com 146 rebanhos em produção, entre os quais foram escolhidos 51 rebanhos. Os rebanhos foram agrupados de acordo com o manejo adotado em cada propriedade e as características de criação. Foram definidos como rebanhos médios $(n=8$; $15,7 \%$ ) os compostos de 50 a 100 vacas, e como rebanhos pequenos $(n=43 ; 84,3 \%)$ os que continham de 10 a 49 vacas. Em $25,5 \%$ dos rebanhos $(n=13)$ eram criados exclusivamente animais da raça Holandesa, enquanto os demais $(n=38 ; 74,5 \%)$ eram formados por gado mestiço. Quarenta produtores $(78,4 \%)$ criavam os bezerros pelo sistema "cria ao pé", sendo estes colocados junto às mães antes do início das ordenhas da manhã e da tarde, para mamar o colostro ou o leite. Após a ordenha, os bezerros eram separados das mães e colocados em piquetes comunitários, reunindo todos os bezerros, independente da idade. O desmame ocorreu em torno do sexto mês de vida. Nos outros rebanhos $(\mathrm{n}=11 ; 21,6 \%)$, os bezerros eram separados das mães 24 horas após o nascimento, alimentados em baldes e alojados em baias individuais até o mínimo de seis semanas de 
idade, quando eram desmamados. A quantidade de leite fornecido variou de quatro a oito litros diários. A partir do sétimo dia, os bezerros passavam a receber água, ração e feno à vontade. Todos os bezerros, independentemente do manejo adotado, permaneceram com as mães durante as primeiras 24 horas de vida para mamar o colostro.

Entre maio e outubro de 2003, foram colhidas 404 amostras de fezes de bezerros. Cada rebanho foi visitado uma única vez, quando foram colhidas amostras de fezes de todos os bezerros, machos e fêmeas, com idades entre um e 45 dias, que apresentavam ou não manifestação clínica de diarreia. A idade dos animais e o período de parição foram determinados pelo registro dos produtores. Foram definidas duas estações de parição: período das chuvas, outubro a março, e período da seca, abril a setembro. As amostras de fezes foram colhidas diretamente da ampola retal em sacos plásticos e acondicionadas em caixas de isopor com gelo. As fezes de consistência líquida foram consideradas diarreicas, e as de consistência firme ou pastosa foram classificadas como não diarreicas. Após a colheita, as amostras foram estocadas a $-20^{\circ} \mathrm{C}$ até a análise laboratorial.

Os bezerros foram agrupados nas faixas etárias de: $1-15,16-30$ e 31-45 dias. Os efeitos de idade, tamanho do rebanho - número de matrizes -, tipo de instalação - bezerreiros comunitários ou individuais -, sistema de alimentação fornecimento de leite em baldes ou "cria ao pé" junto à mãe -, raça - animais puros ou mestiços -, e período de nascimento - período de seca ou período de chuvas - sobre a prevalência de rotavírus foram analisados pelo teste de quiquadrado (Thrusfield, 1985) e estimou-se, também, a associação entre a infecção por rotavírus e a manifestação de diarreia.

A detecção de rotavírus nas amostras de fezes foi realizada por dois métodos: ensaio imunoenzimático (EIE) e eletroforese em gel de poliacrilamida (PAGE). As suspensões fecais foram preparadas a $20 \%$ em tampão tris/cálcio (tris/ $\mathrm{HCl} \quad 0,1 \mathrm{M} ; \mathrm{CaCl} 1,5 \mathrm{mM}, \quad \mathrm{pH} 7,3$ ) e submetidas ao EIE tipo "duplo sanduíche" para a detecção de rotavírus do grupo A, com anticorpo policlonal como captura, de acordo com Pereira et al. (1985) com kit EIARA ( 'Combined Enzyme
Immunoassay for Rotavirus and Adenovirus', Fundação Biomanguinhos, Rio de Janeiro). Simultaneamente, as amostras foram submetidas ao PAGE para detecção e caracterização eletroforética dos segmentos de RNA de dupla fita (dsRNA), de acordo com Pereira et al. (1983). Para visualizar as bandas de dsRNA, o gel de poliacrilamida foi corado com nitrato de prata (Herring et al., 1982).

Amostras fecais positivas para rotavírus no EIE e PAGE foram submetidas à RT-PCR seguida por uma reação de nested PCR multiplex para determinar a característica genotípica das estirpes. O RNA das amostras foi extraído com TRIZOL Reagent ${ }^{\circledR}$ (Gibco BRL) e clorofórmio (Merck). Para a caracterização dos genótipos $\mathrm{G}$ e $\mathrm{P}$, foi utilizada metodologia descrita por Gouvea et al. (1990).

A síntese de DNA complementar (cDNA) foi realizada por transcrição reversa utilizando-se o kit SuperScript ${ }^{\mathrm{TM}}$ One-Step RT-PCR with Platinum $^{\circledR}$ Taq (Invitrogen-Life Technologies), seguindo-se as recomendações do fabricante. Para $50 \mu \mathrm{L}$ de reação, foram utilizados 2x tampão de reação, $1,0 \mu \mathrm{L}$ de RT/Taq Mix, $5 \mu \mathrm{L}$ de RNA e $0,2 \mathrm{mM}$ dos primers. O par de primers Beg 9 e End 9 foi utilizado na síntese de cDNA na genotipagem $\mathrm{G}$, e o par con 2 e con 3 para a genotipagem $\mathrm{P}$. A reação de RT-PCR foi realizada em aparelho Mastercycle (Eppendorf) com um ciclo de $50^{\circ} \mathrm{C}$ por $30 \mathrm{~min}$ e $94^{\circ} \mathrm{C}$ por $2 \mathrm{~min}$, seguida de 35 ciclos de $15 \mathrm{seg}$ a $94^{\circ} \mathrm{C}$, 30 seg a $60^{\circ} \mathrm{C}$, 90 seg a $72^{\circ} \mathrm{C}$ e extensão final de $5 \min$ a $72^{\circ} \mathrm{C}$.

A reação de nested PCR multiplex foi realizada utilizando-se 10x PCR buffer II $(5 \mu \mathrm{L}), 50 \mathrm{mM}$ $\mathrm{MgCl}_{2} \quad(1,5 \mu \mathrm{L}), \quad 4 \mu \mathrm{L}$ de deoxynucleoside triphosphates $2,5 \mathrm{mM}, 4 \mu \mathrm{L}$ da mistura de primers (G ou P), 2,5U Taq DNA polimerase (Invitrogen Life technologies) e $10 \mu \mathrm{L}$ cDNA. Na determinação do genótipo $\mathrm{G}$, foram utilizados os primers DT6, HT8, ET10, FT5, BT11 e o primer sense Beg9. Para a genotipagem $\mathrm{P}$, os primers utilizados foram p/NCDV, p/UK, p/B223, $\mathrm{p} / \mathrm{OSU}, \mathrm{p} / \mathrm{Gott}$ e o primer antisense con 2 (Gouvea et al., 1990; Gentsch et al., 1992; Gouvea et al., 1993; Gouvea et al., 1994a,b).

A reação foi processada em aparelho Mastercycle (Eppendorf) aquecendo a mistura 
por 3 min a $94^{\circ} \mathrm{C}$, seguida de 30 ciclos de $45 \mathrm{seg}$ a $94^{\circ} \mathrm{C}$, 30seg a $50^{\circ} \mathrm{C}$, 90seg a $72^{\circ} \mathrm{C}$ e uma extensão final de $5 \mathrm{~min}$ a $72^{\circ} \mathrm{C}$. Para a genotipagem $\mathrm{G}$, a temperatura de extensão foi de $56^{\circ} \mathrm{C}$.

O produto do nested PCR Multiplex foi analisado em gel de agarose 1,2\% em tampão TBE 1x (0,045M Tris-borate, 0,001M EDTA,pH $8,0)$ corado com brometo de etídeo $1,0 \mu \mathrm{g} / \mathrm{mL}$.

Foram utilizadas como padrão as estirpes NCDV (Nebraska Calf Diarrhoea Vírus - G6P[1]) e KK3 - G10P[11] de rotavírus bovino, cedidas pelo Prof. Dr. José Antônio Jerez, do Departamento de Medicina Veterinária Preventiva e Saúde Animal da USP.

\section{RESULTADOS}

Rotavírus bovino do grupo A foi detectado pelo EIE e/ou PAGE em 11 dos 51 rebanhos amostrados, o que representa prevalência de $21,6 \%$ (11/51). Bezerros foram considerados positivos para rotavírus quando amostras de fezes continham partículas virais detectadas por qualquer uma das técnicas. A prevalência de rotavírus entre os animais amostrados foi de $6,7 \%$, com presença de bezerros positivos tanto em animais com diarreia quanto em bezerros aparentemente saudáveis (Tab. 1). A frequência de infecção foi diferente para cada uma das faixas etárias, sendo maior em animais mais jovens, nas idades entre um e 15 dias, e observou-se relação inversa entre a frequência de positividade e a idade $(\mathrm{P}<0,05)$.

Tabela 1. Frequência de rotavírus nas diferentes faixas etárias dos bezerros e manifestação clínica de diarreia em bezerros de rebanhos leiteiros

\begin{tabular}{cccccccccc}
\hline Idade & \multicolumn{3}{c}{ Bezerros com diarreia } & \multicolumn{3}{c}{ Bezerros sem diarreia } & \multicolumn{3}{c}{ Total de bezerros } \\
\cline { 2 - 10 } (dias) & $\mathrm{N}$ & Positivos & $\%$ & $\mathrm{~N}$ & Positivos & $\%$ & $\mathrm{~N}$ & Positivos & $\%$ \\
\hline 1 a 15 & 47 & 13 & 27,7 & 99 & 6 & 6,0 & 146 & 19 & 13,0 \\
16 a 30 & 45 & 6 & 13,3 & 104 & 1 & 1,0 & 149 & 7 & 4,7 \\
31 a 45 & 11 & 0 & 0 & 98 & 1 & 1,0 & 109 & 1 & 0,9 \\
Total & 103 & 19 & 18,4 & 301 & 8 & 2,7 & 404 & 27 & 6,7 \\
\hline
\end{tabular}

A distribuição das variáveis analisadas está apresentada na Tab. 2. Tamanho do rebanho, tipo de alojamento e sistema de alimentação foram variáveis que representaram fatores de risco quando analisados pelo teste $\chi^{2}(\mathrm{P}<0,05)$. Nos rebanhos pequenos, com até 49 vacas, $4,3 \%$ dos bezerros eliminaram rotavírus, enquanto nos rebanhos grandes, com mais de 50 vacas, 9,2\% estavam infectados. Grupo genético dos animais e estação de parição, pelo $\chi^{2}(\mathrm{P}>0,05)$, não constituíram fatores de risco para a infecção por rotavírus (Tab. 2). Bezerros criados individualmente ou que receberam leite no balde apresentaram maior porcentagem de eliminação de rotavírus.

Tabela 2. Variáveis consideradas na análise dos fatores de risco na prevalência de rotavírus em rebanhos bovinos leiteiros de municípios do estado de São Paulo

\begin{tabular}{|c|c|c|c|c|}
\hline \multirow{2}{*}{ Variável } & & \multirow{2}{*}{$\mathrm{N}$} & \multicolumn{2}{|c|}{ Positivos* } \\
\hline & & & $\mathrm{N}$ & $\%$ \\
\hline \multirow[t]{2}{*}{ Grupo genético: } & Puro & 191 & 17 & 8,9 \\
\hline & Mestiço & 213 & 10 & 4,7 \\
\hline \multirow[t]{2}{*}{ Tamanho do rebanho: } & Pequeno (1-49 vacas) & 208 & 9 & 4,3 \\
\hline & Grande (50-100 vacas) & 196 & 18 & 9,2 \\
\hline \multirow[t]{2}{*}{ Tipo de alojamento: } & Bezerreiro comunitário & 256 & 10 & 3,9 \\
\hline & Bezerreiro individual & 148 & 17 & 11,4 \\
\hline \multirow{2}{*}{ Alimentação: } & Junto à mãe & 256 & 10 & 3,9 \\
\hline & Leite no balde & 148 & 17 & 11,4 \\
\hline \multirow[t]{2}{*}{ Estação de parição: } & $\begin{array}{l}\text { Período da seca } \\
\text { (abril-setembro) }\end{array}$ & 334 & 24 & 7,2 \\
\hline & Período da chuva (outubro-março) & 70 & 3 & 4,3 \\
\hline
\end{tabular}

*Diferença significativa entre grupos pelo $\chi^{2}(\mathrm{P}<0,05)$. 
Dentre as 27 amostras positivas pelo PAGE, sete perfis genômicos foram identificados, todos característicos de rotavírus do grupo A. Pelo método de semi-nested PCR multiplex, foi possível a identificação do genótipo em 18 amostras $(66,6 \%)$. Nos bezerros infectados, um único genótipo $\mathrm{G}$ e $\mathrm{P}$ foi identificado, sendo que os genótipos G6 e G10 estavam presentes em $81,8 \%$ e $18,2 \%$ das amostras, respectivamente, enquanto $75 \%$ eram $\mathrm{P}[5]$ e $25 \%$ P[11]. A associação entre os genótipos $\mathrm{G}$ e $\mathrm{P}$ mostrou que as estirpes de rotavírus circulantes nos rebanhos eram G6P[5] e G10P[11] (Tab. 3).

Tabela 3. Resultados da genotipagem G e P pela reação de nested RT-PCR de amostras de rotavírus de rebanhos bovinos leiteiros

\begin{tabular}{lllll}
\hline Genótipo & $\mathrm{P}[5]$ & $\mathrm{P}[11]$ & Não P & Total \\
\hline G6 & 13 & & 3 & 16 \\
G10 & & 2 & 9 & 2 \\
Não G & & 2 & 12 & 9 \\
Total & 13 & 27 & 27 \\
\hline
\end{tabular}

\section{DISCUSSÃO E CONCLUSÕES}

A diarreia neonatal é um dos principais problemas sanitários que acometem os bezerros nas primeiras semanas de vida (Woode e Bridger, 1975). A associação entre rotavírus do grupo A e a síndrome diarreica já foi descrita em vários países (Snodgrass et al., 1986; Bellinzoni et al., 1989; Costa Mendes et al., 1993), entretanto, apesar da significativa disseminação do vírus, informações de sua prevalência no campo são muito limitadas. Em razão da falta de informações, este trabalho tem importância para a compreensão do comportamento epidemiológico da rotavirose e das variáveis envolvidas com a infecção e manutenção do agente nos rebanhos.

Neste estudo, a prevalência do rotavírus sugere sua disseminação entre rebanhos e a circulação do vírus no ambiente. No entanto, o número de amostras contendo rotavírus foi menor que o obtido em outros países (Snodgrass et al., 1986; Bellinzoni et al., 1989). A presença de animais sem sinais clínicos que eliminam rotavírus nas fezes é de grande relevância epidemiológica, uma vez que sugere a presença de animais infectados subclinicamente e que podem atuar como fontes de infecção para os outros bezerros (Fijtman et al., 1987). Outro fato a ser questionado é que as técnicas de EIE e PAGE utilizadas no presente estudo são muito sensíveis e podem detectar partículas de rotavírus nas fezes mesmo quando os bezerros já passaram pela fase aguda da doença. $\mathrm{Na}$ rotavirose, a grande quantidade de partículas virais eliminadas nas fezes e o longo período de eliminação são fatores que contribuem para elevar a contaminação ambiental e dificultam o controle da infecção nos rebanhos (Bridger, 1994).

Dentre as variáveis consideradas importantes na epidemiologia da rotavirose, a idade dos animais foi um fator significativo $(\mathrm{P}<0,05)$. $\mathrm{O}$ fato de os animais mais jovens, com idade entre um e 15 dias, apresentarem maior taxa de infecção indica maior susceptibilidade dos bezerros nas duas primeiras semanas de vida e precocidade da infecção por rotavírus (McNulty e Logan, 1983). Essa observação está relacionada à deficiência de imunidade dos animais recém-nascidos, que dependem da transferência passiva de anticorpos maternos, principalmente a das classes IgG1 e IgA. Para a imunização eficiente, as fêmeas devem ser vacinadas no final da gestação para que, no momento do parto, o título de anticorpos alcance níveis protetores (Fernandes et al., 1998). Nos rebanhos amostrados, apenas um adotava a vacinação de fêmeas gestantes contra rotavirose como parte do programa de manejo sanitário. Assim, a exposição dos animais logo após o nascimento em um ambiente de alta circulação viral justifica a frequência de infecção observada.

Nos rebanhos maiores concentrou-se a maioria das amostras positivas, sugerindo que neles há maior pressão de infecção, a qual interfere na prevalência da doença, fato também observado por DeLeew et al. (1980). Os sistemas de alimentação e o tipo de abrigo interferiram na frequência de infecção dos bezerros. Nas propriedades que adotavam o manejo de bezerros em baias individuais e que forneciam alimentação em baldes, foram encontradas as maiores frequências de animais infectados por 
rotavírus, sugerindo que nessas propriedades o número elevado de animais favoreceu o ciclo de infecção do rotavírus, o que aumenta a probabilidade de surtos. Em rebanhos pequenos, a menor concentração de bezerros e os intervalos entre nascimentos mais espaçados explicam, em parte, os valores mais baixos de infecção encontrados (Lucchelli et al., 1992).

A raça dos animais e a estação de parição foram fatores que não apresentaram associação com a rotavirose. Com relação à estação de parição, $82,7 \%$ das amostras colhidas (334/404) foram obtidas no período de abril a setembro - período de seca -, enquanto apenas 17,3\% (70/404) foram colhidas no período de outubro a março período de chuva -, época em que as condições de higiene são mais deficientes.

A principal característica da infecção por rotavírus do grupo A foi o predomínio de infecções com os genótipos G6P[5] em três rebanhos e G10P[11] em um rebanho. A identificação de rotavírus dos genótipos G6 e G10 é relatada em diversos países como as principais estirpes associadas à infecção em bezerros (Snodgrass et al., 1990; Ishizaki et al., 1995; Fukay et al., 2002), destacando-se também a sua participação nos rebanhos brasileiros (Brito et al., 2000; Alfieri et al., 2004). Da mesma forma, estirpes com os genótipos P[5] e P[11] são cada vez mais associadas à infecção, assumindo importância em surtos de rebanhos bovinos de diferentes países (Huang et al., 1992; Fukay et al., 2002; Alfieri et al., 2004). Entretanto, o número de amostras positivas no PAGE e não genotipadas na RT-PCR foi muito elevado (33,4\%). Uma das razões está no fato de que no RNA extraído das fezes pode ocorrer coprecipitação de substâncias inibidoras que atuam nos primeiros passos de amplificação (Gouvea et al., 1990), o que pode ser melhorado quando se trabalha com amostras isoladas em cultura de células. Também deve ser destacada a influência da quantidade de RNA necessária para amplificação. A maioria das amostras não genotipadas também não foram eletrofenotipadas no PAGE em razão da pequena quantidade de RNA extraído das fezes, a qual resultou no aparecimento de bandas muito claras, o que, segundo Alfieri et al. (2006), sugere baixo título viral. Não se pode deixar de considerar a possibilidade de que as amostras não genotipadas possam pertencer a estirpes de rotavírus com genótipos diferentes daqueles utilizados nesse levantamento.

Os resultados encontrados neste trabalho mostram que, nos rebanhos leiteiros do Brasil, existem condições favoráveis para a disseminação do rotavírus: elevada contaminação ambiental, rebanhos com número elevado de animais e manejo que favorece a transmissão do agente, associado a uma taxa de imunização inexpressiva. Esses fatores justificam a prevalência determinada e a dificuldade para controlar a infecção e a disseminação do vírus.

\section{AGRADECIMENTOS}

À FAPESP pelo apoio financeiro; ao médico veterinário Dr. Takashi e ao Sr. Marcelo, da Cooperativa de Laticínios de São Carlos e Rio Claro (Colascric), pelo suporte na execução do trabalho de campo.

\section{REFERÊNCIAS BIBLIOGRÁFICAS}

ALFIERI, A.F.; ALFIERI A.A.; BARREIROS, M.A.B. et al. $\mathrm{G}$ and $\mathrm{P}$ genotypes of group $\mathrm{A}$ rotavirus strains circulating in calves in Brazil, 1996-1999. Vet. Microbiol., v.99, p.167-173, 2004.

ALFIERI, A.A.; PARAZZI M.E.; TAKIUCHI, E. et al. Frequency of rotavirus um diarrhoeic calves in Brazilian catlle herds, 1998-2002. Trop. Anim. Health Prod., v.38, p.521-526, 2006.

BELLINZONI, R.C.; BLACKHALL, J.O.; MATTION, N.M. et al. Serological characterization of bovine rotaviruses isolated from dairy and beef herds in Argentina. J. Clin. Microbiol., v.27, p.2619-2623, 1989.

BUZINARO, M.G.; MUMFORD, V.; BRITO, V.M.E.D. et al. Caracterização eletroforética e análise de subgrupo de rotavírus em rebanhos bovinos leiteiros do estado de São Paulo. Arq. Bras. Med. Vet. Zootec., v.52, p.555-561, 2000.

BRIDGER, J.C. A definition of bovine rotavirus virulence. J. Gen. Virol., v.75, p.2807-2812, 1994. 
BRITO, W.M.E.D.; MUNFORD, V.; VILLAÇA, A.M. et al. Characterization of mixed infections with diferent strains of bovine rotavirus in an outbreak of diarrhea in dairy herds in Goiás, Brazil. Braz. J. Microbiol., v.31, p.140-145, 2000.

COSTA MENDES, V.M.; BEER, M.; PEENZE, I. et al. Molecular epidemiology and subgroup analysis of bovine group A rotaviruses associated with diarrhea in South African calves. J. Clin. Microbiol., v.31, p.3333-3335, 1993.

DeLEEW, P.W.; ELLENS, D.J.; STRAVER, P.J. et al. Rotavirus infection in calves in dairy herds. Res. Vet. Sci., v.29, p.135-141, 1980.

ESTES, M.K.; COHEN, J. Rotavirus gene structure and function. Microbiol. Rev., v.53, p.410-449, 1989.

FERNANDEZ, F.M.; CONNER, M.E.; HODGINS, D.C. et al. Passive immunity to bovine rotavirus in newborn calves fed colostrum supplements from cows immunized with recombinant SA11 rotavirus core-like particle (CLP) or virus-like particles (VLP) vaccines. Vaccine, v.16, p.507-516, 1998.

FIJTMAN, N.L.; BARRANDEGUY, M.E.; CORNAGLIA, E.M. et al. Variations and persistency of electropherotypes of bovine rotavirus field isolates. Arch. Virol., v.96, p.275281, 1987.

FUKAY, K.; MAEDA, Y.; FUJIMOTO, K. et al. Changes in the prevalence of rotavirus $G$ and $P$ types in diarrheic calves from the Kagoshima prefecture in Japan. Vet. Microbiol., v.86, p.343349, 2002.

GENTSCH, J.R.; GLASS, R.I.; WOODS, P. et al. Identification of group A rotavirus gene 4 types by polymerase chain reaction. J. Clin. Microbiol., v.30, p.1365-1373, 1992.

GOUVEA, V.; GLASS, R.I.; WOODS, P. et al. Polymerase chain reaction amplification and typing of rotavirus nucleic acid from stool specimens. J. Clin. Microbiol., v.28, p.276-282, 1990.

GOUVEA, V.; RAMIREZ, C.L.L.B.; SANTOS, N. et al. Restriction endonuclease analysis of the VP7 genes of human and animal rotaviruses. $J$. Clin. Microbiol., v.31, p.917-923, 1993.
GOUVEA, V.; SANTOS, N.; TIMENETSKY, M.C. Identification of bovine and porcine rotavirus G types by PCR. J. Clin. Microbiol., v.32, p.1338-1340, 1994a.

GOUVEA, V.; SANTOS, N.; TIMENETSKY, M.C. VP4 typing of bovine and porcine group A roteviruses by PCR. J. Clin. Microbiol., v.32, p.1333-1337, 1994b.

HERRING, A.J.; INGLIS, N.F.; OJEH, C.K. et al. Rapid diagnosis of rotavirus infection by direct detection of viral nucleic acid in silverstained polyacrylamide gels. J. Clin. Micobiol., v.16, p.473-477, 1982.

HUANG, J.A.; NAGESHA, H.S.; SNODGRASS, D.R. et al. Molecular and serological analyses of two bovine rotaviruses (B-11 and B-60) causing calf scours in Australia. J. Clin. Microbiol., v.30, p.85-92, 1992.

ISHIZAKI, H.; OHTA, C.; SHIRAHATA, T. et al. Persistence of a single electropherotype and serotype (G6P5) of bovine rotavirus in calves on a closed dairy farm from 1990 to 1993. Am. J. Vet. Res., v.56, p.1019-1024, 1995.

KLINGENBERG, V.; SVENSSON, L. Group A rotavirus as a cause of neonatal calf enteritis in Sweden. Acta Vet. Scand., v.39, p.195-199, 1998.

LUCCHELLI, A.; LANCE, S.E.; BARTLETT, P.B. et al. Prevalence of bovine group A rotavirus shedding among dairy calves in Ohio. Am. J. Vet. Res., v.53, p.169-174, 1992.

McNULTY, M.S.; LOGAN E.F. Longitudinal survey of rotavirus infection in calves. Vet. Rec., v.13, p.33-35, 1983.

PEREIRA, H.G.; AZEREDO, R.S.; LEITE, J.P.G. et al. Eletrophoretic study of the genome of human rotaviruses from Rio de Janeiro, São Paulo and Pará, Brazil. J. Hyg., v.80, p.117-125, 1983.

PEREIRA, H.G.; AZEREDO, R.S.; LEITE, J.P.G. et al. A combined enzyme immunoassay for rotavirus and adenovirus (EIARA). J. Virol. Methods, v.10, p.21-28, 1985.

REYNOLDS, D.J.; MORGAN, J.H.; CHANTER $\mathrm{N}$. et al. Microbiology of calf diarrhoea in sourthern Britain. Vet. Rec., v.12, p.34-39, 1986. 
SNODGRASS, D.R.; TERZOLO, H.R.; SHERWOOD, D. Aetiology of diarrhoea in young calves. Vet. Rec., v.119, p.31-34, 1986.

SNODGRASS, D.R.; FITZGERALD, T.; CAMPBELL, I. et al. Rotavirus serotypes 6 and 10 predominate in cattle. J. Clin. Microbiol., v.28, p.504-507, 1990.

TANIGUCHI, K.; URASAWA, T.; URASAWA

$S$. Independent segregation of the VP4 and the
VP7 genes in bovine rotaviruses as confirmed VP4 sequence analysis of G8 and G10 bovine rotavirus strains. J. Gen. Virol., v.74, p.12151221, 1993.

THRUSFIELD, M. Veterinary Epidemiology. Cambridge: Blackwell Science, 1985. 479p.

WOODE, G.N.; BRIDGER, J.C. Viral enterits of calves. Vet. Rec., v.96, p.85-88, 1975. 